\title{
Tissue mechanics and expression of TROP2 in oral squamous cell carcinoma with varying differentiation
}

Baoping Zhang ${ }^{1,2+}$, Shuting Gao ${ }^{1 \dagger}$, Ruiping $\mathrm{Li}^{1 \dagger}$, Yiting $\mathrm{Li}^{1}$, Rui Cao ${ }^{1}$, Jingyang Cheng ${ }^{1}$, Yumeng Guo ${ }^{1}$, Errui Wang ${ }^{1}$, Ying Huang ${ }^{1}$ and Kailiang Zhang ${ }^{1 *}$ (D)

\begin{abstract}
Background: Trophoblast cell surface antigen 2 (TROP2) is overexpressed in many squamous cell carcinomas and promotes tumor development and invasion. The association between TROP2 expression and occurrence and development of oral squamous cell carcinoma (OSCC) remains to be understood.

Methods: We investigated the role of TROP2 in OSCC patients using a combination of biophysical approaches. A total of 108 OSCC patient specimens with varying degrees of differentiation were subjected to hematoxylin and eosin staining, immunohistochemistry, Kaplan-Meier survival curve analysis, and atomic force microscopy to analyze TROP2 expression, morphology, and mechanical properties of OSCC tissues.

Results: TROP2 was overexpressed in 34\% of poorly differentiated OSCC samples. High levels of TROP2 were associated with $10.2 \%$ survival rate lower than $45.4 \%$ and patient age (odds ratio [OR] $=0.437, P=0.039,95 \%$ confidence interval $[\mathrm{Cl}, 0.198-0.966])$, tumor size $(\mathrm{OR}=13.148, P=0.000,95 \% \mathrm{Cl}[5.060-34.168])$, and TNM stage $(\mathrm{OR}=0.141, P=0.000,95 \% \mathrm{Cl}[0.082-0.244])$. Average surface roughness of low, medium, and highly differentiated OSCC tissues were $448.9 \pm 54.8,792.7 \pm 83.6$, and $993.0 \pm 104.3 \mathrm{~nm}$, respectively. The Pearson coefficient revealed a negative association between tumor stiffness and TROP2 expression $(r=-0.84, P<0.01)$.

Conclusion: Overexpression of TROP2 negatively associated with patient survival, degree of tumor differentiation, and tissue mechanics. Taken together, our findings demonstrated that TROP2 may be an indicator of OSCC differentiation leading to the altered mechanical properties of OSCC tissues.
\end{abstract}

Keywords: Oral squamous cell carcinoma, TROP2, Tissue stiffness, Differentiation, Survival

\section{Background}

Oral squamous cell carcinoma (OSCC) is a common subtype of head and neck and other malignant tumors $[1,2]$. The past few decades have shown increased incidence of OSCC that is expected to rise further in the future [3]. Therefore, it is imperative to determine

\footnotetext{
* Correspondence: zhangkllzu@163.com

${ }^{\dagger}$ Baoping Zhang, Shuting Gao and Ruiping Li contributed equally to this work.

'Department (Hospital) of Stomatology, Lanzhou University, Donggang west Road 199, Lanzhou 730000, Gansu, China

Full list of author information is available at the end of the article
}

biological factors associated with the early diagnosis and treatment of OSCC.

Human trophoblast cell surface antigen 2 (TROP2), also called tumor-associated calcium signal transduction-2 (TACSTD-2), is a surface glycoprotein encoded by TACS TD that has extracellular domains, a single transmembrane domain, and a short tail $[4,5]$. TROP2 is overexpressed in many human cancers, including ovarian [6,7], gastric [8, 9], colorectal [10], pancreatic [11], and laryngeal cancers [12]. Inhibiting TROP2 expression has shown promise in clinical applications $[13,14]$. TROP2 regulates

(C) The Author(s). 2020 Open Access This article is licensed under a Creative Commons Attribution 4.0 International License, which permits use, sharing, adaptation, distribution and reproduction in any medium or format, as long as you give appropriate credit to the original author(s) and the source, provide a link to the Creative Commons licence, and indicate if changes were made. The images or other third party material in this article are included in the article's Creative Commons licence, unless indicated otherwise in a credit line to the material. If material is not included in the article's Creative Commons licence and your intended use is not permitted by statutory regulation or exceeds the permitted use, you will need to obtain permission directly from the copyright holder. To view a copy of this licence, visit http://creativecommons.org/licenses/by/4.0/ The Creative Commons Public Domain Dedication waiver (http://creativecommons.org/publicdomain/zero/1.0/) applies to the data made available in this article, unless otherwise stated in a credit line to the data. 
tumorigenic properties including cancer cell adhesion, invasion, and migration. Tang et al. [15] have recently shown that TROP2 impacts growth and metastasis by activating PI3K/AKT signaling. This phenomenon has also been observed in gallbladder cancer [16]. Among the various biochemical mechanisms involved in tumorigenesis, the role of $\beta$-catenin has been studied extensively $[8,17-19]$. This has shed light on the biological functions of TROP2 and its use as a prognostic biomarker for OSCC.

Atomic force microscopy (AFM) is a powerful tool that generates surface topographical images with magnifications that range between macro- and nanoscales. AFM has been used to determine the mechanical properties of tumor tissues in a variety of cancers, such as those of the breast [20], liver [21], and lung [22]. Parameters for tissue stress, such as mechanical phenotype index, correlate with cancer development and invasion [23]. Advancements in technology used for determining biophysical properties have facilitated the nano-level analysis of tumor tissues.
This study aims at investigating the correlation between TROP2 expression and clinicopathological characteristics of OSCC. We have demonstrated the tissue morphology and mechanics of OSCC samples during tumor development using AFM. We believe our findings will help develop TROP2 in accurately diagnosing OSCC in tumors with different grades of differentiation.

\section{Methods}

\section{Tissue preparation}

The protocols in this study were approved by the research ethics committee of Lanzhou University. Tumor samples were collected from patients after obtaining written informed consent. A total of 108 patients with oral squamous cell carcinoma (OSCC) were registered at the second hospital of Lanzhou University between January 2013 and March 2019. Among these samples, 36 samples each showed high, moderate, and low levels of differentiation. The experimental group comprised 60 males and 48 females aged 41-68 years (average: 51 years). All patients were diagnosed with OSCC based on surgery and

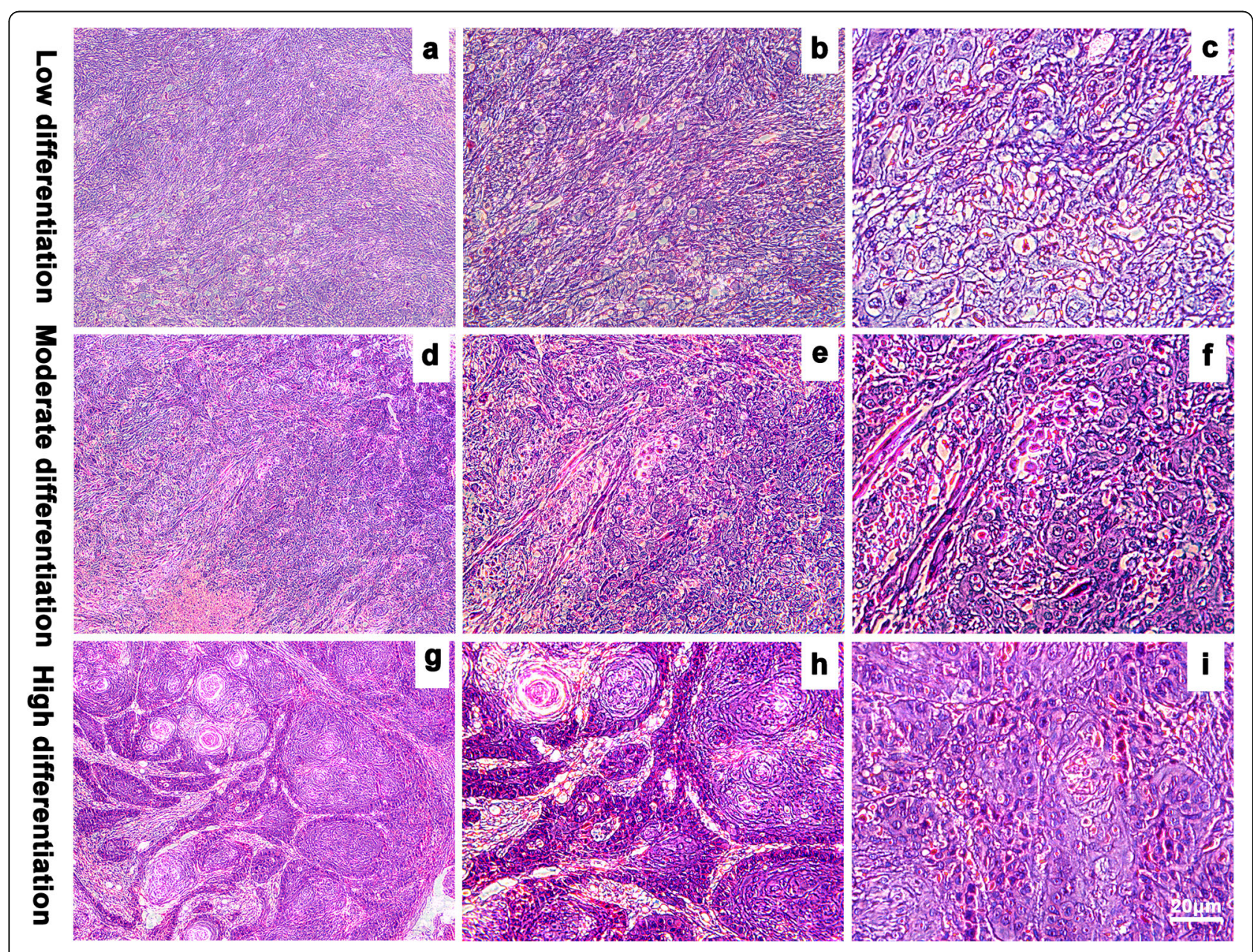

Fig. 1 Paraffin pathological sections of tissues ( $a, d, g$, $\times 4$-fold; b, e, h, $\times 10$-fold; c, f, i, $\times 40$-fold) 


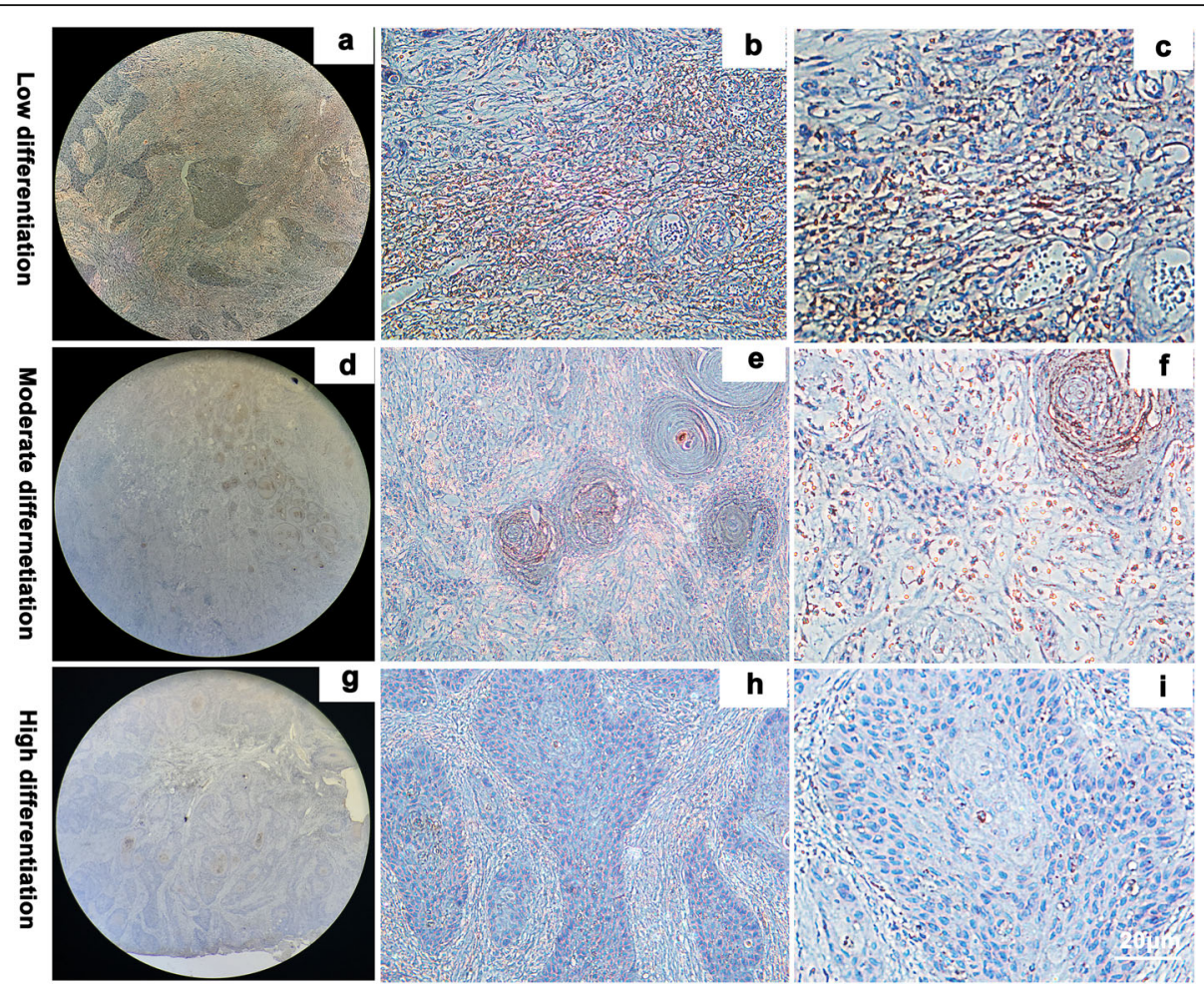

Fig. 2 Immunohistochemical staining was performed to detect the expression of TROP2 at different stages of OSCC

pathology; patients did not undergo radiotherapy, chemotherapy, or immunotherapy before surgery. Pathological analysis after tumor biopsy was performed by two experienced pathologists, after which the diagnosis of other diseases (including inflammation at other sites and secondary tumors) were excluded. Cancer and cervical lymph node tissues were collected after maxillofacial surgery. All specimens were sampled from typical areas of the lesion and fixed with $10 \%$ neutral-buffered formalin followed by conventional paraffin embedding. Among them, 42 and 66

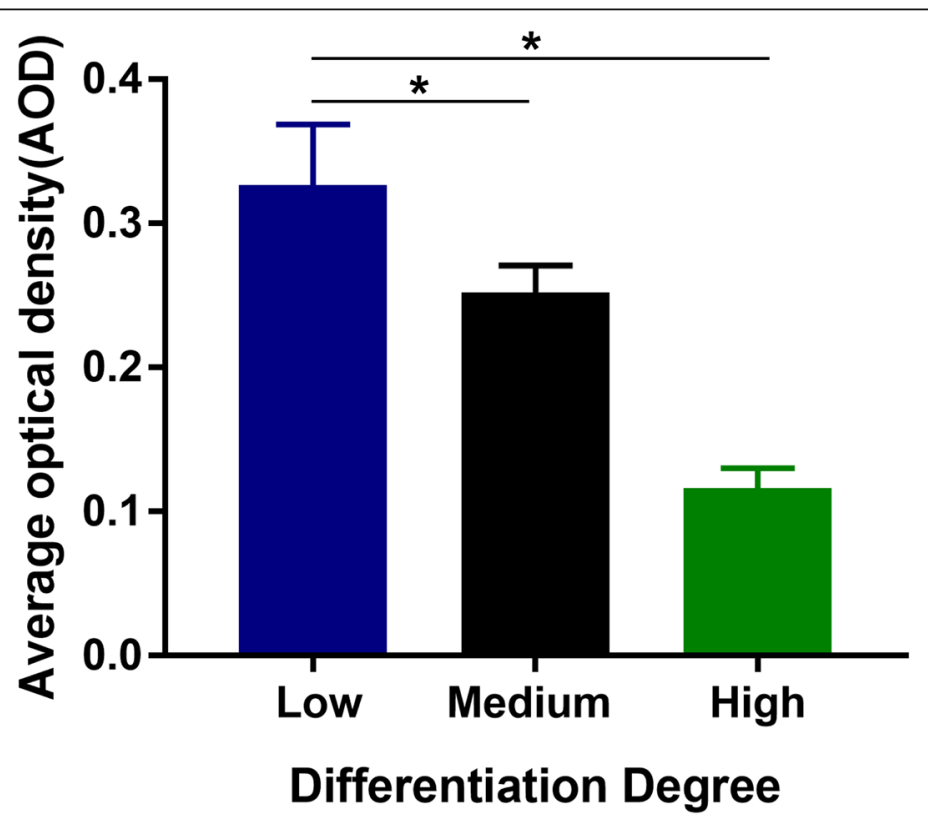

Fig. 3 Average optical density of TROP2, poorly differentiated squamous cell carcinoma showed high expression $(P<0.05)$ 
Table 1 Correlation between TROP2 expression and clinicopathological characteristics

\begin{tabular}{|c|c|c|c|c|c|}
\hline \multirow[t]{2}{*}{ Characters } & \multirow[t]{2}{*}{$n$} & \multicolumn{2}{|c|}{ TROP2 expression(\%) } & \multirow[t]{2}{*}{ Pearson $x^{2}$} & \multirow[t]{2}{*}{$P$ value } \\
\hline & & Low or no(\%) & High(\%) & & \\
\hline Total & 108 & 67 & 41 & & \\
\hline Gender & & & & 0.786 & 0.375 \\
\hline Male & 60 & 35 & 25 & & \\
\hline Female & 48 & 32 & 16 & & \\
\hline Age & & & & 4.254 & 0.039 \\
\hline$\geq 50$ & 61 & 43 & 18 & & \\
\hline$<50$ & 47 & 24 & 23 & & \\
\hline Localization & & & & 2.217 & 0.136 \\
\hline mucosa & 21 & 16 & 5 & & \\
\hline Tongue & 87 & 51 & 36 & & \\
\hline Differentiation & & & & 77.268 & $<0.001$ \\
\hline well & 36 & 35 & 1 & & \\
\hline Moderate & 36 & 31 & 5 & & \\
\hline Poor & 36 & 2 & 34 & & \\
\hline Tumor size & & & & 32.883 & $<0.001$ \\
\hline $\mathrm{T} 1 \leq 2 \mathrm{~cm}$ & 59 & 51 & 8 & & \\
\hline $2 \mathrm{~cm}<\mathrm{T} 2 \leq 4 \mathrm{~cm}$ & 49 & 16 & 33 & & \\
\hline $\mathrm{T} 3>4 \mathrm{~cm}$ & 0 & 0 & 0 & & \\
\hline T4b & 0 & 0 & 0 & & \\
\hline Lymph node metastases & & & & 2.574 & 0.109 \\
\hline No & 42 & 30 & 12 & & \\
\hline$N_{x}$ & 66 & 37 & 29 & & \\
\hline Distant metastases & & & & 1.015 & 0.314 \\
\hline MO & 70 & 41 & 29 & & \\
\hline M1 & 38 & 26 & 12 & & \\
\hline TNM stage & & & & 67.880 & $<0.001$ \\
\hline$|+1|$ & 78 & 67 & 11 & & \\
\hline$I I I+I V$ & 30 & 0 & 30 & & \\
\hline Perineural infiltration & & & & 16.881 & $<0.001$ \\
\hline No & 91 & 64 & 27 & & \\
\hline Yes & 17 & 3 & 14 & & \\
\hline Vascular invasion & & & & 27.688 & $<0.001$ \\
\hline No & 45 & 41 & 4 & & \\
\hline Yes & 63 & 26 & 37 & & \\
\hline
\end{tabular}

patients exhibited no and cervical lymph node metastases, respectively. Clinical TNM staging was performed according to the 7th edition TNM staging classification standard jointly developed by the International Union for Cancer Control and American Joint Committee on Cancer [24] and World Health Organization guidelines [25].

\section{Hematoxylin and eosin (H\&E) staining}

OSCC tissues were fixed overnight using 10\% neutral formalin (Solarbio, Beijing, China), paraffin embedded, sliced into 4- $\mu \mathrm{m}$ thick sections, dewaxed using xylene, and rehydrated using different concentrations of ethanol. The sections were stained with hematoxylin for $5 \mathrm{~min}$ and hydrochloric acid-ethanol and eosin for 3 min followed by gradient dehydration, transparentization, sealing, and neutral resin sealing (Solarbio, Beijing, China). Sections were visualized and imaged using the Olympus BX53 at magnifications of $\times 10$, 20 , and 40 . 


\section{Immunohistochemistry}

HE sections were subjected to the S-P method to detect TROP2 expression. The sections were incubated overnight with the primary antibody against TROP2 (1:1000, Abcam, USA) at $4{ }^{\circ} \mathrm{C}$ followed by incubation with biotin-labeled goat anti-rabbit IgG (1:5000, Abcam, USA) at $37^{\circ} \mathrm{C}$ for $1 \mathrm{~h}$. The sections were then developed using DAB (Beijing Zhongshan Golden Bridge Biotechnology, China), dehydrated, transparentization, and film and neutral resin sealed. The prepared sections were visualized using microscopy (Olympus BX53, Japan).

\section{AFM}

Fixed tissues were placed in Petri dishes containing phosphate-buffered saline. All analyses for mechanical properties were performed using the biological atomic force microscope (BioAFM; NanoWizard III, Bruker, USA). Silicon AFM probes from the Pointprobe $^{\circ}$ series with a force constant of $0.2 \mathrm{~N} / \mathrm{m}$ (CONTR-reflex coating, NanoWorld, USA) were used. The spring constant of the probe was calibrated using built-in thermal vibration before measuring the resonance frequency of $13 \mathrm{kHz}$ and thickness of $2 \mu \mathrm{m}$. AFM was performed using the contact model and a scan rate of $0.5 \mathrm{~Hz} / \mathrm{s}$ in air. Force-distance curves are generated when the probe contacts the tissue following which, the structure, morphology, and mechanical properties of samples are measured at $5 \mu \mathrm{m} / \mathrm{s}$ [26]. Six random sites were selected for each sample and each site was measured 15 times. We used the modified Hertz contact model to analyze force-distance curves [27] and calculate Young's modulus and roughness of OSCC tissues with varying differentiation.

\section{Statistical analysis}

Statistical analyses were performed using SPSS 22.0 (Statistical Product and Service Solutions, IBM). Force spectrum data were expressed as mean \pm standard error and statistical comparisons were performed using oneway analysis of variance followed by the Tukey-Kramer HSD test for pair-wise comparisons. Pearson Chi-square test was used to analyze clinical features and TROP2 expression based on the calculated odds ratios (ORs) and 95\% confidence interval (CI). Survival was evaluated using Kaplan-Meier curves and the difference was analyzed using the log-rank test. $P<0.05$ was considered statistically significant.

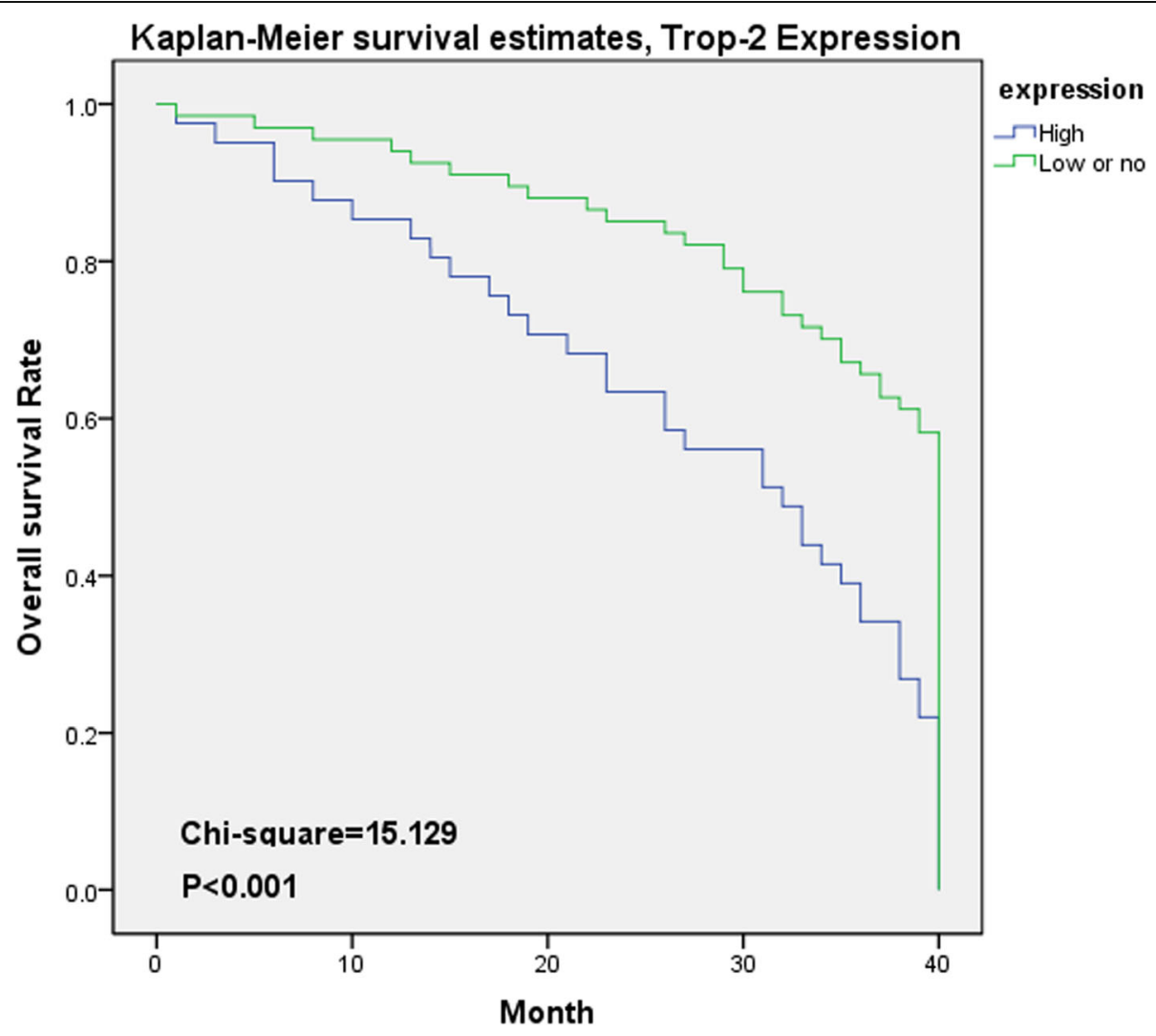

Fig. 4 TROP2 total survival curve using Kaplan-Meier survival curves (low blue line, high green line) 


\section{Results}

Tissue morphology and TROP 2 expression across the clinical stages of OSCC

Tumor cells from poorly differentiated OSCC samples exhibited characteristic atypia, poor differentiation, and irregular morphology (Fig. 1). However, the number, volume, atypia, nuclear pyknosis, and mitotic structures decreased in tumor cells from highly differentiated OSCC as compared to those in poorly differentiated cells. TROP2 primarily localized in the cytoplasm of tumor cells, but not in adjacent normal epithelial cells. We observed that low differentiation and high malignancy of OSCC was associated with higher TROP2 expression (Fig. 2). The average optical density of TROP2 among the low, medium, and highly differentiated OSCC tissues were $0.32 \pm 0.042, \quad 0.25 \pm 0.018$, and $0.11 \pm 0.013$, respectively (Fig. 3).

Table 2 TROP2 expression risk factors with clinicopathological features

\begin{tabular}{|c|c|c|c|c|c|}
\hline \multirow[t]{2}{*}{ Characteristics } & \multirow[t]{2}{*}{$\mathrm{n}$} & \multicolumn{2}{|c|}{ TROP2 expression(\%) } & \multirow[t]{2}{*}{$P$ value } & \multirow[t]{2}{*}{ OR $(95 \% \mathrm{Cl})$} \\
\hline & & Low or no(\%) & $\operatorname{High}(\%)$ & & \\
\hline Total & 108 & 67 & 41 & & \\
\hline Gender & & & & 0.375 & $1.429(0.649,3.147)$ \\
\hline Male & 60 & 35 & 25 & & \\
\hline Female & 48 & 32 & 16 & & \\
\hline Age & & & & 0.039 & $0.437(0.198,0.966)$ \\
\hline$\geq 50$ & 61 & 43 & 18 & & \\
\hline$<50$ & 47 & 24 & 23 & & \\
\hline Localization & & & & 0.136 & $0.443(0.149,1.318)$ \\
\hline Mucosa & 21 & 16 & 5 & & \\
\hline Tongue & 87 & 51 & 36 & & \\
\hline \multicolumn{6}{|l|}{ Differentiation } \\
\hline Well & 36 & 35 & 1 & $>0.05^{a}$ & $5.645(0.625,50.987)$ \\
\hline Moderate & 36 & 31 & 5 & $<0.001^{b}$ & $105.400(19.053,583.063)$ \\
\hline Poor & 36 & 2 & 34 & $<0.001^{c}$ & $595.000(51.529,6870.366)$ \\
\hline Tumor size & & & & $<0.001$ & $13.148(5.060,34.168)$ \\
\hline $\mathrm{T} 1 \leq 2 \mathrm{~cm}$ & 59 & 51 & 8 & & \\
\hline $2 \mathrm{~cm}<\mathrm{T} 2 \leq 4 \mathrm{~cm}$ & 49 & 16 & 33 & & \\
\hline $\mathrm{T} 3>4 \mathrm{~cm}$ & 0 & 0 & 0 & & \\
\hline $\mathrm{T} 4 \mathrm{~b}$ & 0 & 0 & 0 & & \\
\hline Lymph node metastases & & & & 0.109 & $1.959(0.857,4.482)$ \\
\hline $\mathrm{N}_{0}$ & 42 & 30 & 12 & & \\
\hline $\mathrm{N}_{\mathrm{X}}$ & 66 & 37 & 29 & & \\
\hline Distant metastases & & & & 0.314 & $0.653(0.284,1.501)$ \\
\hline MO & 70 & 41 & 29 & & \\
\hline M1 & 38 & 26 & 12 & & \\
\hline TNM stage & & & & $<0.001$ & $0.141(0.082,0.244)$ \\
\hline $\mid+\|$ & 78 & 67 & 11 & & \\
\hline$I I I+I V$ & 30 & 0 & 30 & & \\
\hline Perineural infiltration & & & & $<0.001$ & $11.062(2.939,41.641)$ \\
\hline No & 91 & 64 & 27 & & \\
\hline Yes & 17 & 3 & 14 & & \\
\hline Vscular invasion & & & & $<0.001$ & $14.587(4.653,45.729)$ \\
\hline No & 45 & 41 & 4 & & \\
\hline Yes & 63 & 26 & 37 & & \\
\hline
\end{tabular}

Note: ${ }^{a}$, Well vs Moderate, ${ }^{b}$, Moderate vs Poor, ${ }^{c}$, Well vs Poor 


\section{Association between TROP2 expression and clinical characteristics of OSCC}

We analyzed the clinicopathological characteristics of patients with OSCC with varying degree of differentiation. Differential expression of TROP2 was associated with patient age, tumor differentiation, tumor size, TNM stage, percutaneous nerve filtration, and vascular invasion (Table $1, P<0.05$ ). Patients with poorly differentiated tumors were more likely than patients with well and moderate differentiated tumors to have high TROP2 expression $(P<0.001)$. However, there was no association between the expression of TROP2 and patient gender, tumor location, lymph node metastasis, or distant metastases $(P>0.05)$.

\section{TROP2 expression and patient survival}

Using Kaplan-Meier survival curves, we observed that an increase in TROP2 expression negatively correlated with the overall survival of patients (Fig. 4). And low/no of
TROP2 expression group's 3-years survival rate was $55.6 \%$, a $20.4 \%$ for high expression group and 5-years rate were 45.4 and $10.2 \%$ respectively. TROP2 expression was associated with patient age $(P=0.039, \mathrm{OR}=0.437,95 \% \mathrm{CI}$ [0.198-0.966]), tumor differentiation (Well vs. Moderate, $P>0.05, \mathrm{OR}=5.645,95 \%$ CI [0.625-50.987]; Moderate vs. Poor, $P<0.001$, OR $=105.400,95 \%$ CI [19.053-583.063]; Well vs. Poor, $P<0.001$, OR $=595.000$, 95\% CI [51.5296870.366]), tumor size $(P<0.05, \mathrm{OR}=13.148,95 \% \mathrm{CI}$ [5.060-34.168]), TNM stage $(P<0.05$, OR $=0.141,95 \% \mathrm{CI}$ $[0.082-0.244])$, vascular invasion $(P<0.05, \mathrm{OR}=14.587$, 95\% CI [4.653-45.729]), and peripheral nerve invasion $(P<0.05$, OR $=11.062$, Table 2$)$. High TROP2 expression was detected in older patients with low degree of differentiation, larger tumor volume, higher TNM staging, and vascular and peripheral nerve invasion, thereby resulting in lower overall survival. Thus, TROP2 may be a prognostic indicator for survival in OSCC patients.

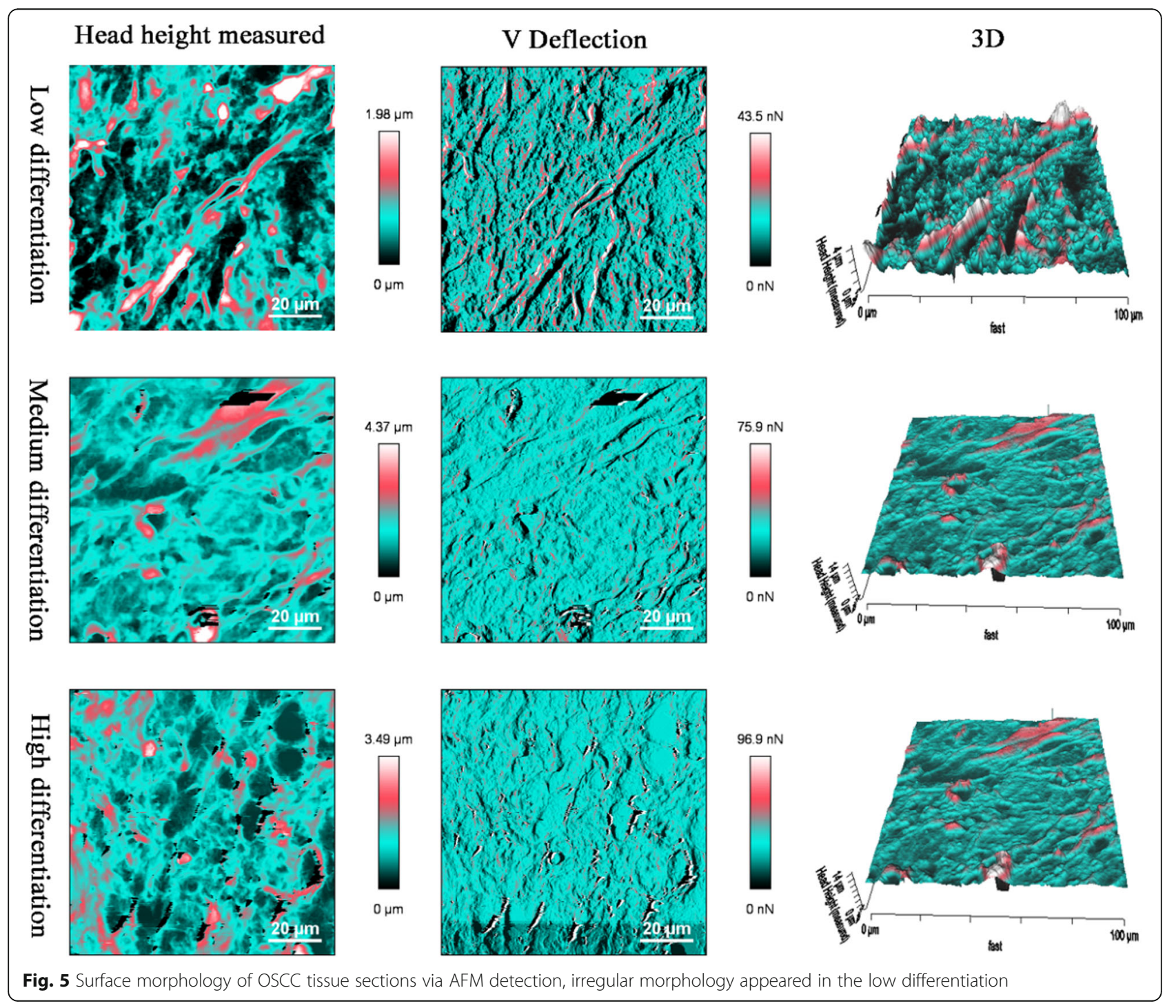


Surface morphology and roughness of OSCC tissues The surface morphologies of OSCC tissues with varying degrees of differentiation were analyzed (direct topographical imaging) using BioAFM. Figure 5 shows the representative image from each tissue acquired during the cantilever-based AFM nano- indentation test. The tissue interface varied with tumor differentiation, indicating that highly differentiated OSCC tissues had a regular and flat morphology. OSCC tissues with low differentiation exhibited an overall irregular morphology with distinct modulation and loose tissue organization. Figure 6 summarizes the roughness of OSCC tissues with varying differentiation. The average surface roughness of low, medium, and highly differentiated OSCC tissues were 448.9 $\pm 54.8,792.7 \pm$ 83.6 , and $993.0 \pm 104.3 \mathrm{~nm}$, respectively. Roughness of the tissue surface was enhanced with increasing differentiation of OSCC tissues.

\section{Young's modulus of OSCC tissues}

We used BioAFM to determine Young's modulus based on the mechanical properties of 108 OSCC tissues with varying degrees of differentiation. We randomly selected six contact points from each slice and each contact point was measured 15 times. Forcedistance curves were generated for each slice and the JPK Data Processing software (5.1.8 version) was used to calculate Young's modulus. Figure 7 shows the average variation in stiffness within individual tissues in the range of $1-8 \mathrm{kPa}$. In the low differentiation samples, we observed low stiffness as compared to that in high or medium differentiation samples $(P<$
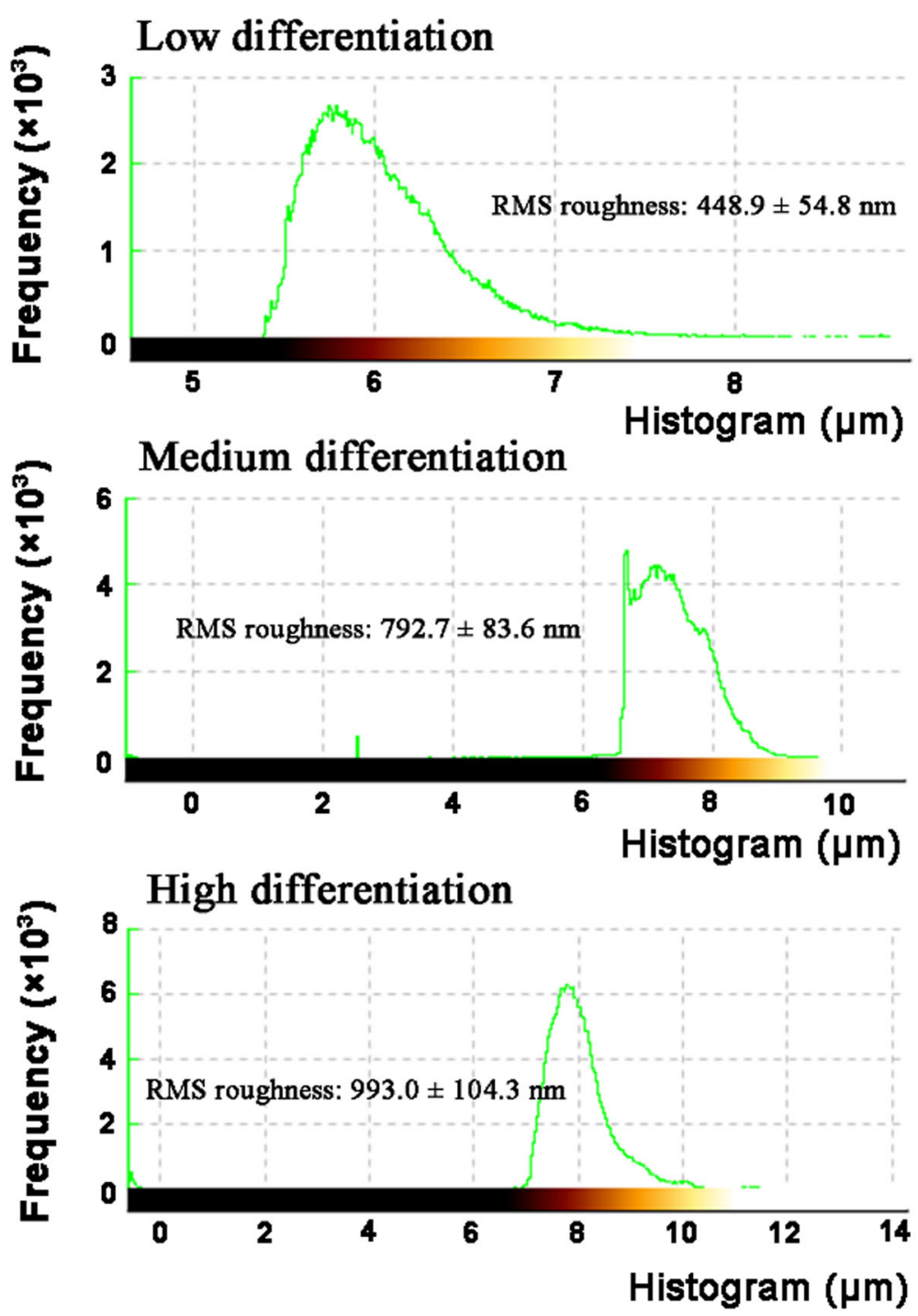

Fig. 6 Surface roughness, results are express as mean \pm SEM nm 


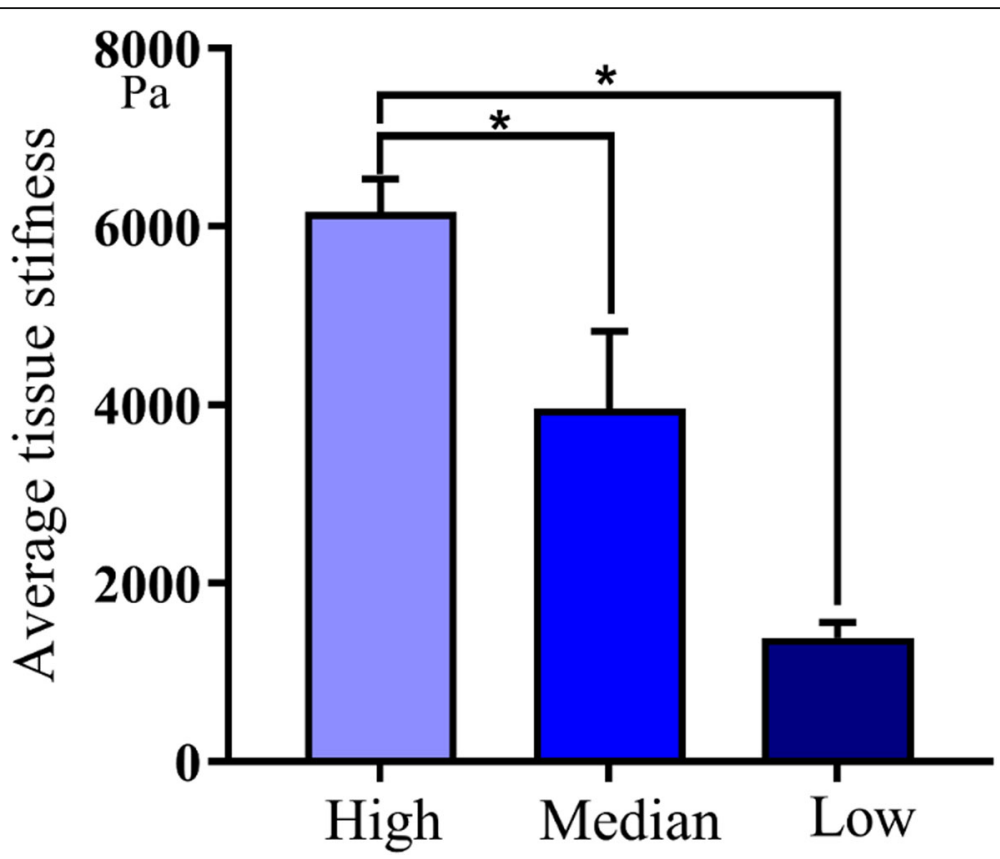

Fig. 7 AFM test average tissue stiffness. Young's modulus, E, was thus confirmed to be a parameter of cell hardness for various cells and tissue $(\mathrm{Pa}, P<0.05)$

0.05). Thus, tissue differentiation was positively associated with its stiffness (Fig. 7).

\section{Association between mechanical properties and TROP2 expression in OSCC}

The Pearson coefficient showed a negative association between the stiffness of OSCC tissues and TROP2 expression (Fig. 8, $r=-0.84, P<0.01$ ). Thus, we detected an increase in stiffness with varying differentiation in the tumor samples.

\section{Discussion}

TROP2 belongs to the family of genes involved in calcium signaling associated with tumorigenesis and found in human trophoblast and chorionic cell lines. Studies have shown that overexpression of TROP2 is associated with tumorigenesis and malignancy [28-30]. In this study, TROP2 expression was observed to be a highly sensitive and specific marker of tongue squamous cell carcinoma and tissue stiffness. The relative thickness of samples helped accurately diagnose and determine the staging of tongue squamous cell carcinoma.

Immunohistochemical analysis revealed that the expression of TROP2 in poorly differentiated OSCC tissues was significantly higher than that in well-differentiated OSCC tissues. Additionally, TROP2 upregulation was correlated with tumors of advanced TNM (III + IV) staging and poor differentiation than that in tumors with low TNM (I + II) staging. Thus, the abnormal expression of TROP2 may be associated with the occurrence and development of tongue malignancies. Furthermore, high TROP2 expression predicted low survival as compared to that in the tumors with low TROP2 expression. Previous research has also demonstrated the correlation between shorter patient lifespan and high levels of TROP2 as compared to that in patients with laryngeal squamous cell carcinoma and low levels of TROP2 [31]. TROP2 possesses sites for tyrosine/serine phosphorylation that regulate signal transduction or its expression and activity, thereby rendering cancer cells resistant to apoptosis [32]. Upregulated TROP2 correlates with the poor prognosis of thyroid papillary carcinoma [33], colon cancer [34], liver cancer [35], and other malignancies.

There have been an increasing number of studies on the biological role of TROP2 at the molecular level. TROP2 induces the downregulation/loss of PTEN, thereby stimulating PI3K/AKT signaling and tumor development [15]. PTEN is a well-known tumor suppressor that is a phosphatase [36] and affects the PI3K/PKB/AKT signaling axis during the dephosphorylation of PIP-2 and PIP-3 [37]. PI3K signaling is important in regulating tumor cell proliferation, migration, and invasion [38, 39]. Thus, PTEN is a negative regulator of cancer $[40,41]$. Li et al. have shown that TROP2 activates epithelial-mesenchymal transition via PI3K/AKT signaling, thereby promoting proliferation, migration, and metastasis in gallbladder cancer [42]. Similarly, TROP2 expression stimulates the proliferation, migration, and invasion of osteosarcoma cells [43]. Hou et al. demonstrated that TROP2 regulates JAK2/STAT3 signaling in glioblastoma cells [44]. 


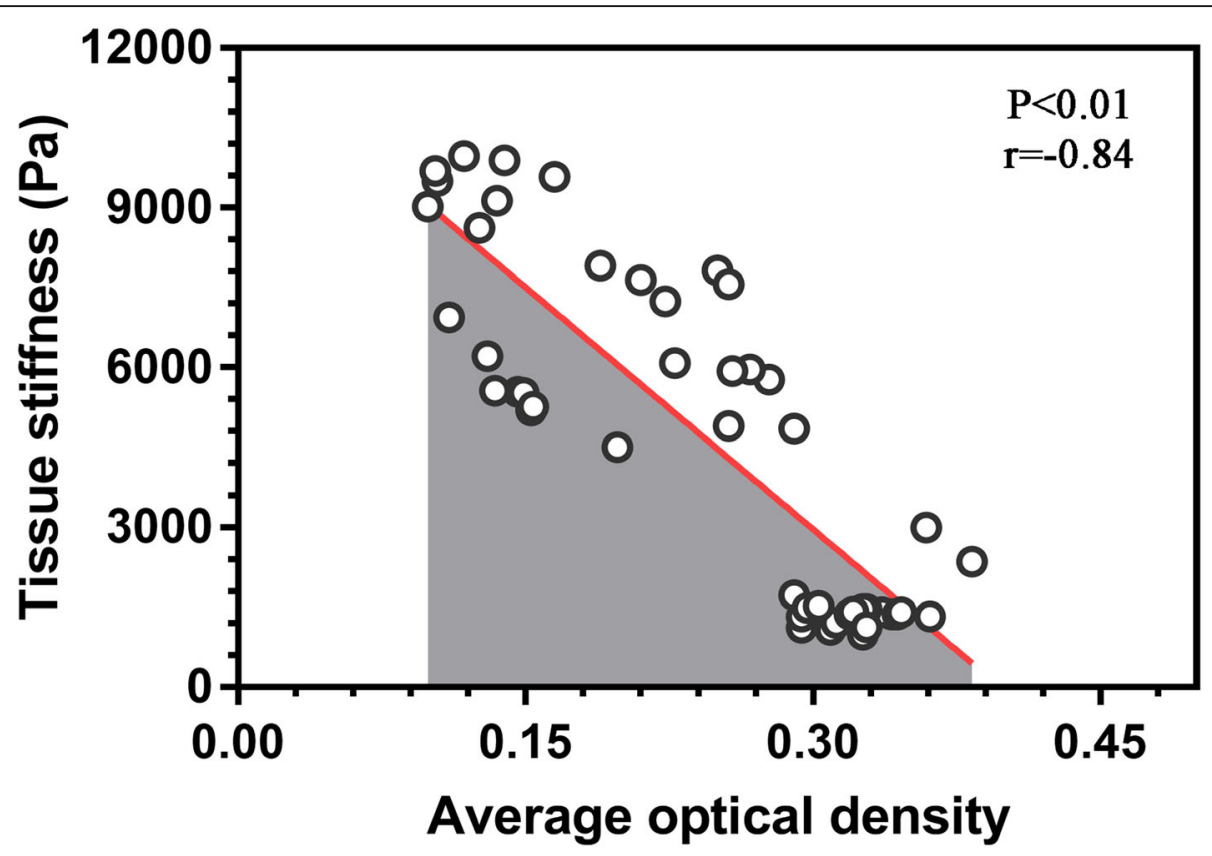

Fig. 8 Correlation analysis between changes in mechanical stiffness of OSCC tissues and TROP2 expression Note: changes have statistical significance $(P<0.01)$ and show a certain negative correlation $(r=-0.84)$

Functional differentiation of tissues influences the micro-morphology and mechanical stiffness of OSCC cells. We detected low surface roughness on OSCC tissues with loose structure, reduced hardness, and enhanced cell adhesion, migration, and invasion. Poorly differentiated OSCC tissues are "softer" than highly differentiated OSCC tissues. PI3K is an important celladhesion molecule. TROP2 triggers the synthesis of proteins with homologous domains, such as pleckstrin, RAC, Tiam, and Vav. Tiam and Vav activate RAC that leads to reorganization of the actin cytoskeleton, cell recognition, and adhesion [45].

The underlying mechanisms involved in the alteration of micromechanical properties of OSCC samples and occurrence, development, metastasis, and invasion of OSCC tumors remain to be elucidated. H\&E staining is the gold standard for tumor diagnosis. With the development of biomechanics in the past two decades [46, 47], the mechanical properties of tissues need to be investigated based on biomedical and physical parameters. In this study, we have assayed the changes in mechanical properties at the micro-nanometer level using AFM and determined the association between the TNM grade, metastasis, and stiffness of tumor samples.

In conclusion, we have demonstrated the association between differential expression of TROP2 and patient age, tumor differentiation, tumor size, TNM stage, percutaneous nerve filtration, and vascular invasion. Moreover, high levels of TROP2 correlated with poor overall survival in patients. Highly differentiated cancer tissues exhibited increased surface roughness and stiffness. Lastly, high TROP2 expression resulted in reduced tumor stiffness. However, this study had some limitations. First, the cohort used in this study was relatively small. Second, we did not employ molecular methods of analysis such as western blotting or enzyme-linked immunosorbent assay. Thus, using a larger patient cohort and multiple techniques in molecular and cell biology will help validate our findings and develop TROP2 as a specific and efficient prognostic biomarker for OSCC.

\section{Conclusion}

These findings could promote new methods for the early OSCC diagnosis depend on the stage of cancer and developing screening methods with high sensitivity and specificity. More detailed studies are needed to determine the feasibility and therapeutic benefit of testing tissue stiffness in human disease.

\section{Abbreviations \\ OSCC: Oral squamous cell carcinoma; TROP2: Trophoblast cell surface antigen 2; AFM: Atomic force microscopy}

\section{Acknowledgements \\ We thank the individual who participated in this study.}

\section{Authors' contributions}

BZ, SG and RPL are responsible for conception and design. Data was collected by YTL, RC, JYC and YMG. Data was analyzed by EW and YH. KLZ revised the article. All authors have read and approved the manuscript.

\section{Funding}

This work was supported by the Fundamental Research Funds for the Central Universities (No. Izujbky-2020-cd03, Baoping Zhang), Doctoral/master 
students of the Second Hospital of Lanzhou University (sdkygg-17, Lan Yang), and Key Laboratory of Mechanics on Disaster and Environment in Western China, The Ministry of Education of China (No. 2019-06, Kailiang Zhang).

\section{Availability of data and materials}

The datasets used and analyzed during the current study are available from the corresponding author on reasonable request.

\section{Ethics approval and consent to participate}

Written informed consent was obtained from each participant before sample collection. The study was approved by the Committee for Ethical Affairs of School of Stomatology, Lanzhou University.

\section{Consent for publication}

Not applicable.

\section{Competing interests}

The authors have no conflicts of interest.

\section{Author details}

'Department (Hospital) of Stomatology, Lanzhou University, Donggang west Road 199, Lanzhou 730000, Gansu, China. ${ }^{2}$ Institute of Biomechanics and Medical Engineering, Lanzhou University, Lanzhou 730000, China.

Received: 13 April 2020 Accepted: 4 August 2020

Published online: 27 August 2020

\section{References}

1. Iyer S, Thankappan K, Balasubramanian D. Early detection of oral cancers: current status and future prospects. Curr Opin Otolaryngol Head Neck Surg. 2016;24(2):110-4.

2. Caldeira PC, Soto AML, de Aguiar MCF, Martins CC. Tumor depth of invasion and prognosis of early-stage oral squamous cell carcinoma: a meta-analysis. Oral Dis. 2019. Online ahead of print.

3. Kim Y, Kim JH. Increasing incidence and improving survival of oral tongue squamous cell carcinoma. Sci Rep. 2020:10:7877.

4. McDougall AR, Tolcos M, Hooper SB, Cole TJ, Wallace MJ. Wallace. Trop2: from development to disease. Dev Dyn. 2015;244(2):99-109.

5. Guan GF, Zhang DJ, Wen LJ, Yu DJ, Zhao Y, Zhu L, et al. Prognostic value of TROP2 in human nasopharyngeal carcinoma. Int J Clin Exp Pathol. 2015;8(9): 10995-1004

6. Stewart D, Cristea M. Antibody-drug conjugates for ovarian cancer: current clinical development. Curr Opin Obstet Gynecol. 2019;31(1):18-23.

7. Liu J, Yang D, Yin Z, Gao M, Tong H, Su Y, et al. A novel human monoclonal Trop2-lgG antibody inhibits ovarian cancer growth in vitro and in vivo. Biochem Biophys Res Commun. 2019;512(2):276-82.

8. Zhao W, Jia L, Kuai $X$, Tang Q, Huang $X$, Yang $T$, et al. The role and molecular mechanism of Trop2 induced epithelial-mesenchymal transition through mediated beta-catenin in gastric cancer. Cancer Med. 2019;8(3): 1135-47.

9. Zhao W, Jia L, Zhang M, Huang X, Qian P, Tang Q, et al. The killing effect of novel bi-specific Trop2/PD-L1 CAR-T cell targeted gastric cancer. Am J Cancer Res. 2019;9(8):1846-56.

10. Jordheim LP, Chettab K, Cros-Perrial E, Matera EL, Dumontet C. Unexpected growth-promoting effect of oxaliplatin in excision repair crosscomplementation group 1 transfected human colon cancer cells. Pharmacology. 2018;102(3-4):161-8.

11. Nishimura T, Mitsunaga M, Sawada $R$, Saruta M, Kobayashi H, Matsumoto $N$, et al. Photoimmunotherapy targeting biliary-pancreatic cancer with humanized anti-TROP2 antibody. Cancer Med. 2019;8(18):7781-92.

12. Wang $X D$, Wang $Q$, Chen $X L$, Huang JF, Yin $Y$, Da $P$, et al. Trop2 inhibition suppresses the proliferation and invasion of laryngeal carcinoma cells via the extracellular signal-regulated kinase/mitogen-activated protein kinase pathway. Mol Med Rep. 2015;12(1):865-70.

13. Wanger TM, Dewitt S, Collins A, Maitland NJ, Poghosyan Z, Knauper V. Differential regulation of TROP2 release by PKC isoforms through vesicles and ADAM17. Cell Signal. 2015;27(7):1325-35.

14. Chen X, Pang B, Liang Y, Xu SC, Xin T, Fan HT, et al. Overexpression of EpCAM and Trop2 in pituitary adenomas. Int J Clin Exp Pathol. 2014;7(11): 7907-14.
15. Tang G, Tang Q, Jia L, Chen $Y$, Lin L, Kuai $X$, et al. TROP2 increases growth and metastasis of human oral squamous cell carcinoma through activation of the PI3K/Akt signaling pathway. Int J Mol Med. 2019:44(6):2161-70.

16. Trerotola M, Li J, Alberti S, Languino LR. TROP2 inhibits prostate cancer cell adhesion to fibronectin through the $\beta 1$ integrin-RACK1 axis. J Cell Physiol. 2012;227(11):3670-7

17. Li T, Su Y, Yu X, Mouniir DSA, Masau JF, Wei X, et al. Trop2 guarantees cardioprotective effects of cortical bone-derived stem cells on myocardial ischemia/reperfusion injury. Cell Transplant. 2018;27(8):1256-68.

18. Stoyanova T, Goldstein AS, Cai H, Drake JM, Huang J, Witte ON. Regulated proteolysis of Trop2 drives epithelial hyperplasia and stem cell self-renewal via beta-catenin signaling. Genes Dev. 2012;26(20):2271-85.

19. Sun X, Xing G, Zhang C, Lu K, Wang Y, He X. Knockdown of Trop2 inhibits proliferation and migration and induces apoptosis of endometrial cancer cells via AKT/ $\beta$-catenin pathway. Cell Biochem Funct. 2020.

20. Lee H, Jang Y, Seo J, Nam JM, Char K. Nanoparticle-functionalized polymer platform for controlling metastatic cancer cell adhesion, shape, and motility. ACS Nano. 2011;5(7):5444-56.

21. Kruse SA, Smith JA, Lawrence AJ, Dresner MA, Manduca A, Greenleaf JF, et al. Tissue characterization using magnetic resonance elastography: preliminary results. Phys Med Biol. 2000;45(6):1579-90.

22. Kaneko TS, Pejcic MR, Tehranzadeh J, Keyak JH. Relationships between material properties and $C T$ scan data of cortical bone with and without metastatic lesions. Med Eng Phys. 2003;25(6):445-54.

23. Goetz JG, Minguet S, Navarro-Lerida I, Lazcano JJ, Samaniego R, Calvo E, et al. (2011) biomechanical remodeling of the microenvironment by stromal caveolin-1 favors tumor invasion and metastasis. Cell. 2011;146:148-63.

24. Edge SB, Compton CC. Compton, the American joint committee on Cancer: the 7th edition of the AJCC cancer staging manual and the future of TNM. Ann Surg Oncol. 2010;17(6):1471-4.

25. Barnes L, Eveson JW, Reichart P, Sidransky D. Pathology \& Genetics Head and Neck Tumours. Lyon: Barness; 2005. p. 254-6.

26. Zhang B, Li L, Li Z, Liu Y, Zhang H, Wang J. Carbon ion-irradiated hepatoma cells exhibit coupling interplay between apoptotic signaling and morphological and mechanical remodeling. Sci Rep. 2016;6:35131.

27. Yan JF, Huang GY. A double-hertz model for adhesive contact between cylinders under inclined forces, Philos. Trans A Math Phys Eng Sci. 2019; 475(2221):20180589.

28. Kowalsky CA, Faber MS, Nath A, Dann HE, Kelly WW, Liu L, et al. Rapid fine conformational epitope mapping using comprehensive mutagenesis and deep sequencing. J Biol Chem. 2015;290(44):26457-70.

29. Zeng P, Chen MB, Zhou LN, Tang M, Liu CY, Lu PH. Impact of TROP2 expression on prognosis in solid tumors: a systematic review and metaanalysis. Sci Rep. 2016;6:33658.

30. Calvo A, Xiao N, Kang J, Best CJ, Leiva I, Emmert-Buck MR, et al. Alterations in gene expression profiles during prostate cancer progression: functional correlations to tumorigenicity and down-regulation of selenoprotein-P in mouse and human tumors. Cancer Res. 2012;62(18):5325-35.

31. Ju X, Jiao X, Ertel A, Casimiro MC, Di Sante G, Deng S, et al. V-Src oncogene induces Trop2 proteolytic activation via Cyclin D1. Cancer Res. 2016;76(22): 6723-34.

32. Cubas R, Li M, Chen C, Yao Q. Trop2: a possible therapeutic target for late stage epithelial carcinomas. Biochim Biophys Acta. 2009;1796(2):309-14.

33. Zargari N, Mokhtari M. Evaluation of diagnostic utility of immunohistochemistry markers of TROP2 and HBME-1 in the diagnosis of thyroid carcinoma. Eur Thyroid J. 2019:8:1-6.

34. Zhao P, Zhang Z. TNF-a promotes colon cancer cell migration and invasion by upregulating TROP2. Oncol Lett. 2018;15(3):3820-7.

35. Sin STK, Li Y, Liu M, Yuan YF, Ma S, Guan XY. Down-regulation of TROP-2 predicts poor prognosis of hepatocellular carcinoma patients. Hepatol Commun. 2018;2(11):1408-14.

36. Zhang $Y$, Zhang R, Luo G, Ai K. Long noncoding RNA SNHG1 promotes cell proliferation through PI3K/AKT signaling pathway in pancreatic ductal adenocarcinoma. J Cancer. 2018;9(15):2713-22.

37. Sai J, Owens P, Novitskiy SV, Hawkins OE, Vilgelm AE, Yang J, et al. PI3K inhibition reduces mammary tumor growth and facilitates antitumor immunity and anti-PD1 responses. Clin Cancer Res 24. 2017; 23(13):3371-3384.

38. Zhang XR, Wang SY, Sun W, Wei C. Isoliquiritigenin inhibits proliferation and metastasis of MKN28 gastric cancer cells by suppressing the PI3K/AKT/ mTOR signaling pathway. Mol Med Rep. 2018;18(3):3429-36. 
39. Wise HM, Hermida MA, Leslie NR. Prostate cancer, PI3K, PTEN and prognosis. Clin Sci (Lond). 2017;131(3):197-210.

40. Yuan B, Zou M, Zhao Y, Zhang K, Sun Y, Peng X. Up-regulation of miR-130b$3 p$ activates the PTEN/PI3K/AKT/NF-KB pathway to defense against mycoplasma gallisepticum (HS Strain) infection of chicken. Int J Mol Sci. 2018; 19(8). pii: E2172.

41. Li JW, Wang XY, Zhang X, Gao L, Wang LF, Yin XH. Epicatechin protects against myocardial ischemiainduced cardiac injury via activation of the PTEN/PI3K/AKT pathway. Mol Med Rep. 2018;17(6):8300-8.

42. Li X, Teng S, Zhang $Y$, Zhang W, Zhang $X$, Xu K, et al. TROP2 promotes proliferation, migration and metastasis of gallbladder cancer cells by regulating PI3K/AKT pathway and inducing EMT. Oncotarget. 2017;8(29): 47052-63.

43. Gu QZ, Nijiati A, Gao X, Tao KL, Li CD, Fan XP, et al. TROP2 promotes cell proliferation and migration in osteosarcoma through PI3K/AKT signaling. Mol Med Rep. 2018;18(2):1782-8.

44. Hou J, Lv A, Deng Q, Zhang G, Hu X, Cui H. TROP2 promotes the proliferation and metastasis of glioblastoma cells by activating the JAK2/ STAT3 signaling pathway. Oncol Rep. 2019;41(2):753-64.

45. Rivard N. Phosphatidylinositol 3-kinase: a key regulator in adherens junction formation and function. Front Biosci (Landmark Ed). 2009;14:510-22.

46. Pankova D, Jiang Y, Chatzifrangkeskou M, Vendrell I, Buzzelli J, Ryan A, et al. RASSF1A controls tissue stiffness and cancer stem-like cells in lung adenocarcinoma. EMBO J. 2019;38(13):e100532.

47. Wullkopf L, West AV, Leijnse N, Cox TR, Madsen CD, Oddershede LB, et al. Cancer cells' ability to mechanically adjust to extracellular matrix stiffness correlates with their invasive potential. Mol Biol Cell. 2018;29(20):2378-85.

\section{Publisher's Note}

Springer Nature remains neutral with regard to jurisdictional claims in published maps and institutional affiliations.

Ready to submit your research? Choose BMC and benefit from:

- fast, convenient online submission

- thorough peer review by experienced researchers in your field

- rapid publication on acceptance

- support for research data, including large and complex data types

- gold Open Access which fosters wider collaboration and increased citations

- maximum visibility for your research: over $100 \mathrm{M}$ website views per year

At $\mathrm{BMC}$, research is always in progress.

Learn more biomedcentral.com/submissions 